\title{
Effects of Flow Rate and Viscosity on Slip Factor of Centrifugal Pump Handling Viscous Oils
}

\author{
Wen-Guang Li \\ Department of Fluid Machinery, Lanzhou University of Technology, 287 Langongping Road, Lanzhou, Gansu 730050, China \\ Correspondence should be addressed to Wen-Guang Li; liwg40@sina.com
}

Received 14 March 2013; Revised 3 June 2013; Accepted 19 June 2013

Academic Editor: Ryoichi Samuel Amano

Copyright (C) 2013 Wen-Guang Li. This is an open access article distributed under the Creative Commons Attribution License, which permits unrestricted use, distribution, and reproduction in any medium, provided the original work is properly cited.

\begin{abstract}
Slip factor is an important parameter in the hydraulic design of centrifugal pump impeller for handling viscous oils. How to extract the factor from CFD computational results and how flow rate and liquid viscosity to affect it remain unclear. In the present paper, the flip factor was estimated by means of two approaches: one is from the velocity triangles at the impeller outlet and the other is due to the impeller theoretical head of 3D turbulent viscous fluid. The velocity of water and viscous oils in the impeller and volute computed by CFD was validated with LDV measurements at the best efficiency point. The effect of exit blade angle on slip factor was clarified. It was shown that the two approaches result into two different slip factors. The factors are significantly dependent of flow rate; however, the liquid viscosity seems to take less effect on them. Volute is responsible for reduction in tangential velocity of liquid at the outlet of impeller at low flow rates. The slip factor of impeller with large exit blade angle is not sensitive to flow rate.
\end{abstract}

\section{Introduction}

The performance of centrifugal pump handling water and viscous oils was investigated numerically by using a CFD code FLUENT based on a steady, 3D, and incompressible turbulent flow. The turbulence effect was involved with the standard $k-\varepsilon$ turbulence model and wall roughness was taken into account with the nonequilibrium wall function in [1]. The effect of liquid viscosity on pump performance was clarified through observing the pump head and hydraulic efficiency as well as hydraulic loss coefficient in terms of flow rate. A comparison of computed and experimental overall performance of the pump was made. It was confirmed that the "sudden-rising head effect" exists and is caused from the high viscosity and certain large surface roughness. The volute results in an increasing influence on the flow around the impeller exit at a low flow rate.

Slip factor is one important design parameter for deciding a correct impeller diameter of centrifugal pump. The factor can be obtained theoretically and experimentally. The typical investigations include those conducted by Kasai $[2$, 3], Sakai and Watanabe [4], Noorbakhsh [5], Whitfield [6],
Murata et al. [7], Harada and Senoo [8], Visser et al. [9], von Backstron [10], Hassenpflug [11], Ji et al. [12], Qiu et al. [13], and so on. The slip factor depends on impeller geometry $[5,7,9,10,14]$, flow rate $[2-4,6,13,15]$, and viscosity of the liquid pumped [16, 17].

Recently, Slip factor is increasingly estimated by using CFD approach [18-22]. Thus it is necessary to explore effects of viscosity and flow rate on slip factor when a centrifugal pump handles viscous oils. The results can be useful and helpful to primary hydraulic design and performance prediction of a viscous oil transporting centrifugal pump by means of a simple and quick method such as the mean line method proposed by Veres [23].

In this paper, it is intended to establish the slip factor dependence upon liquid viscosity and flow rate and show the difference in theoretical head of impeller between CFD and traditional one estimated by the Euler turbomachinery equation and a slip factor correction. Besides, a comparison of LDV measured velocity and CFD computed one in the impeller and volute was presented for water and highly viscous oil at the best efficiency point (BEP) to validate CFD results in the flow field. 


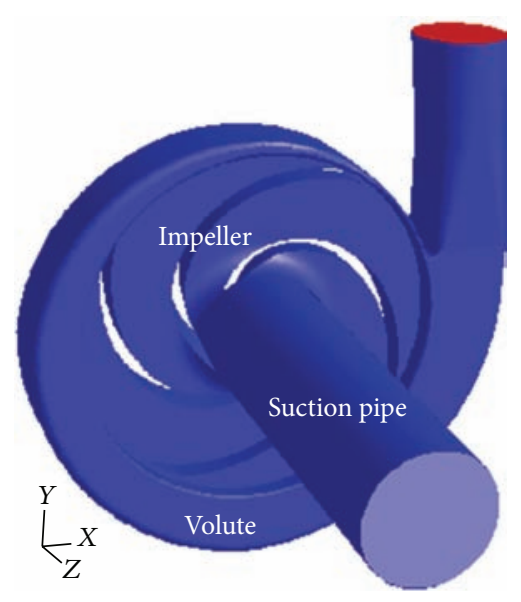

(a)

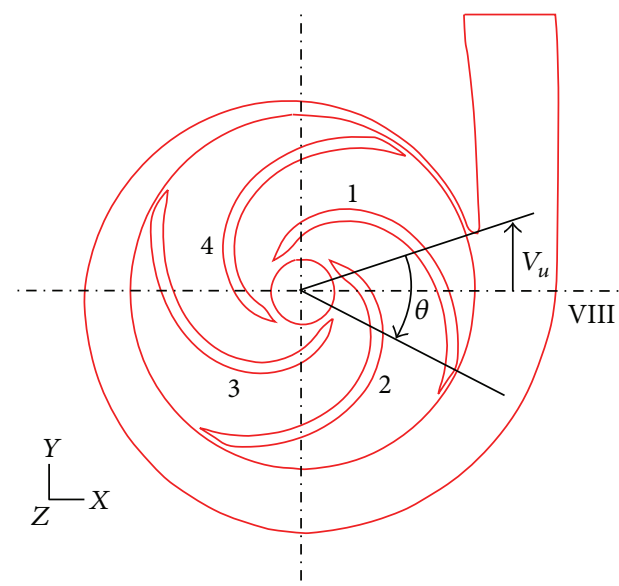

(b)

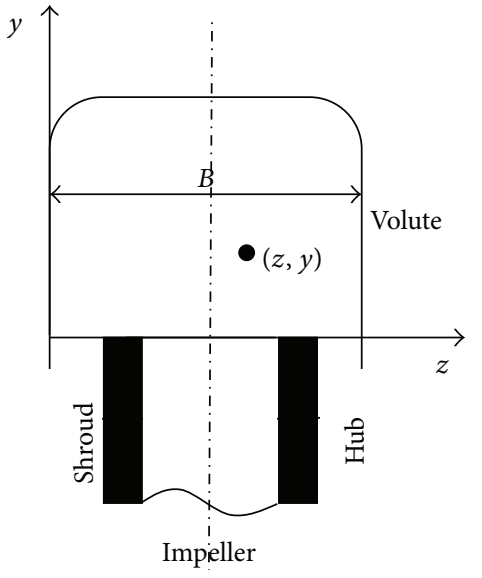

(c)

FIGURE 1: Fluid domain of the model pump (a), the relative position between blade 1 and the volute tongue (b), and a local coordinate system in cross-section VIII (c).

\section{Computational Models and Slip Factor Extraction}

2.1. Computational Models. The computational physical model is the end-suction, single stage centrifugal pump in [1]. The pump flow rate, head, and rotational speed are $Q=25 \mathrm{~m}^{3} / \mathrm{h}, H=8 \mathrm{~m}$ and $n=1450 \mathrm{r} / \mathrm{min}, n_{s}=$ $3.65 n \sqrt{\mathrm{Q}} / H^{3 / 4}\left(\mathrm{r} / \mathrm{min}, \mathrm{m}^{3} / \mathrm{s}, \mathrm{m}\right)=93$ at design point. The impeller eye and outlet diameters are $62 \mathrm{~mm}$ and $180 \mathrm{~mm}$, the number of blades is 4 , the exit blade angle is $20^{\circ}$, and its warp angle is $140^{\circ}$. The diameter of base circle and width of the volute are $190 \mathrm{~mm}$ and $40 \mathrm{~mm}$, and the cross-sectional area of volute throat is $1440 \mathrm{~mm}^{2}$.

The computational fluid domain consists of suction pipe, rotating impeller, and volute, as shown in Figure 1(a). The rotor-stator interfaces are established at the entrance to the impeller and the impeller outlet to couple the flow variables in the impeller and volute. The impeller rotational effect is involved by means of MRF (multiple reference frame) method proposed in FLUENT. For such a flow, the CFD computations were carried out at $\theta=45^{\circ}$, which is the angle between the volute tongue tip and the outer edge of pressure surface of impeller blade.

$3 \mathrm{D}$, steady, and incompressible turbulent flow in the pump was solved by FLUENT. The turbulence effect was taken into account with the standard $k-\varepsilon$ turbulence model, and the wall roughness was involved by the nonequilibrium wall function. The finite volume method, SIMPLE algorithm, and the second-order upwind scheme for the convection terms in the governing equations were adopted. The viscosity and density of liquids are presented in Table 1.

The fluid domain of suction pipe was discretized with hexahedral cells, but those of impeller and volute were meshed with tetrahedral cells. It was found that when the total number of cells was increased up to $910 \mathrm{k}$ ( $10 \mathrm{k}$ in the suction pipe, $380 \mathrm{k}$ in the impeller, and $520 \mathrm{k}$ in the volute), the pump performance became independent of mesh size.

The relaxation factors for the pressure correction equation, momentum equations, and $k$ and $\varepsilon$ transport equations
TABLE 1: Viscosity and density of working liquids.

\begin{tabular}{lcccc}
\hline Liquid & Water & Oil 1 & Oil 2 & Oil 3 \\
\hline Density, $\rho\left(\mathrm{kg} / \mathrm{m}^{3}\right)$ & 1000 & 839 & 851 & 858 \\
Kinetic viscosity, $\nu(\mathrm{cSt})$ & 1.0 & 24.47 & 48.48 & 60.7 \\
Nominal viscosity $(\mathrm{cSt})$ & 1 & 24 & 48 & 60 \\
\hline
\end{tabular}

$1 \mathrm{cSt}=1 \mathrm{~mm}^{2} / \mathrm{s}$

were $0.3,0.5,0.8$, and 0.8 , respectively. The residual tolerances for the pressure correction equation, momentum equations, $k$ and $\varepsilon$ transport equations were $1 \times 10^{-4}$.

There was an inlet velocity boundary condition at the entrance to the suction pipe. The reference pressure is zero. There was an outlet pressure boundary condition at the volute nozzle discharge. The rest boundaries were no-slip solid walls with the roughness $\mathrm{Ra}=50 \mu \mathrm{m}$.

2.2. Slip Factor Extraction. Slip factor is used to specify the flow slip effect in the exit of a centrifugal pump impeller and is a key parameter to establish a theoretical head developed by the impeller. There are several versions of definition for the slip factor. However, the following definition in [24] is accepted in this paper:

$$
\sigma=\frac{\Delta v_{u 2}}{u_{2}}
$$

where the slip velocity of fluid (Figure 2) depends on the impeller geometry and flow rate as well as fluid viscosity, and so forth, and $\Delta v_{u 2}=w_{u 2}-w_{u 2 \infty}, w_{u 2}$ is the relative tangential velocity with slip, whilst $w_{u 2 \infty}$ is the relative tangential velocity without slip. Traditionally, the slip factor of a centrifugal pump impeller is frequently estimated by means of the Wiesner or Stodola formulas. The Wiesner expression is read as in [25]

$$
\sigma=\frac{\sqrt{\sin \beta_{2 b}}}{Z^{0.7}}
$$

and the Stodola's relation is written as [25]

$$
\sigma=\frac{\pi \sin \beta_{2 b}}{Z}
$$




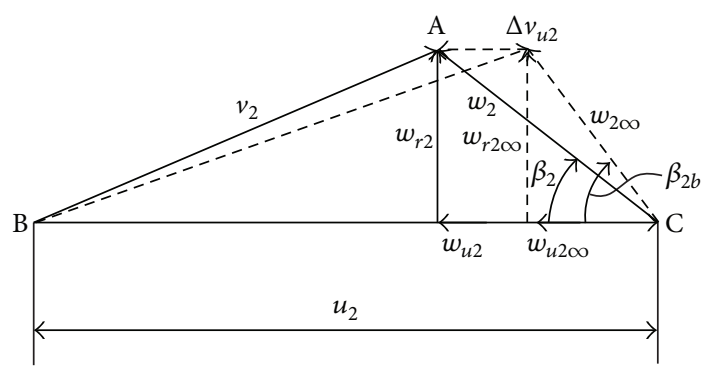

FIGURE 2: Velocity triangle at impeller exit.

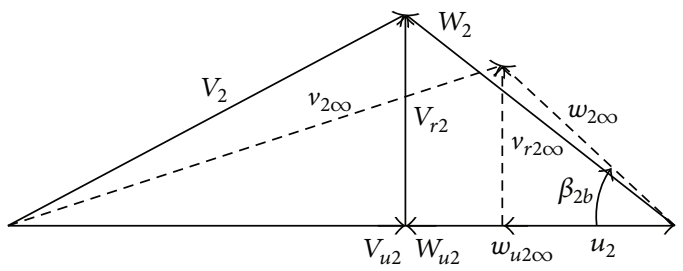

$---1 \mathrm{D}$

$-3 \mathrm{D}$

FIGURE 3: Velocity triangle at impeller discharge for estimate of slip factor.

where $\beta_{2 b}$ is the impeller blade discharge angle. Note that those equations do not involve the effects of both fluid viscosity and flow rate on the slip factor.

A slip factor can be calculated by using a velocity triangle at the impeller discharge in [4]. In addition, it was proposed that the slip factor can be estimated by using the Euler equation of turbomachinery with an actual relative flow angle at the impeller exit given by CFD computations in [19]. In that case, the slip factor is defined by the ratio of the impeller theoretical head over the head of the impeller with infinite number of blades. In that proposal, it was assumed that the $3 \mathrm{D}$ viscous and $1 \mathrm{D}$ ideal flow share the same radial flow velocity component. In experiments in [3], however, 3D viscous fluid flow showed an increasing radial velocity at the impeller exit compared to 1D uniform inviscid flow sketched in Figure 3. The same effect is also observed in CFD computational results in the paper. Thus, we have to apply the velocity triangle in Figure 3 to extract a slip factor.

For a uniform 1D ideal flow, the tangential component of the relative velocity $w_{u 2}$ is given by the following expression:

$$
w_{u 2 \infty}=\frac{v_{r 2 \infty}}{\tan \beta_{2 b}}=\frac{Q}{\eta_{V} A_{2} \psi_{2} \tan \beta_{2 b}},
$$

where $u_{2}$ is the impeller tip speed, $u_{2}=\omega D_{2} / 2, D_{2}$ the impeller diameter, $\eta_{V}$ the volumetric efficiency, $\eta_{V}=0.869$ based on the experiments in [26, 27], $A_{2}$ the impeller exit area, $A_{2}=\pi D_{2} b_{2}, b_{2}$ the blade exit width, $\psi_{2}$ the blade blockage coefficient at exit, $\psi_{2}=1-Z S_{u 2} / \pi D_{2}, S_{u 2}$ the tangential thickness of blade at exit, and $S_{u 2}=10 \mathrm{~mm}$.
Based on the CFD computational results, the velocity components $V_{u 2}, W_{u 2}$, and $V_{r 2}$ are available; thus, the slip velocity $\Delta v_{u 2}$ can be calculated with the following expression:

$$
\Delta v_{u 2}=W_{u 2}-w_{u 2 \infty} .
$$

With the slip factor definition (1), the slip factor extracted from the velocity triangles is expressed by

$$
\sigma_{\Delta}=\frac{W_{u 2}}{u_{2}}-\frac{Q}{\eta_{V} A_{2} \psi_{2} \tan \beta_{2 b} u_{2}} .
$$

It is important to point out that for $3 \mathrm{D}$ viscous fluids the slip factor estimated based on the velocity triangle at the impeller outlet constructed with CFD outcomes does not seem to be linked directly to the impeller theoretical head because the variable $u_{2} V_{u 2} / g$ at the impeller outlet in the Euler equation no longer represents the total energy of the fluids; the details can be found in Section 4.1.

Additionally, we are able to evaluate a slip factor by using the impeller theoretical head of viscous fluids obtained from CFD computations. The impeller theoretical head of 1D fluid flow is written by

$$
H_{i 1 D}=\frac{u_{2}}{g}\left[(1-\sigma) u_{2}-\frac{Q}{\eta_{V} A_{2} \psi_{2} \tan \beta_{2 b}}\right] .
$$

Substituting the theoretical head of viscous fluids $H_{i}$ given by CFD computations into (7) for $H_{i 1 D}$, then a slip factor corresponding to $H_{i}$ is calculated by the following equation:

$$
\sigma_{H}=1-\left(\frac{g H_{i}}{u_{2}^{2}}+\frac{Q}{\eta_{V} u_{2} A_{2} \psi_{2} \tan \beta_{2 b}}\right) .
$$

\section{Results}

3.1. Velocity Validation. For simplicity, the fluid relative velocity vectors measured by using LDV in [27] and predicted by CFD here are shown in Figure 4 for water (1cSt) and oil $(48 \mathrm{cSt})$ at $\operatorname{BEP}(Q=6.0 \mathrm{~L} / \mathrm{s})$ and $\mathrm{Ra}=50 \mu \mathrm{m}$. The vectors lay in the plane that is through the mid-span of blade at trailing edge and perpendicular to the pump shaft. For the experimental and computational velocities, the velocity profile shows a low velocity near the pressure side of blade and a high velocity near the suction side at a small radius. However, as the radius increases, the velocity profile exhibits a high velocity near the pressure side and a low velocity near the suction side.

It is seen that the predicted flow fields of oil appear to show slight difference from water at the same working condition. Importantly, the computed flow fields are insensitive to the change in fluid viscosity. However, this is not true for the measured flow fields of oil.

The 2D, time-averaged, circumferential components of liquid velocity in the volute throat, section VIII, see Figure 1(b), given by LDV measurement in [28] and CFD computation, are shown in Figure 5 at BEP and $\mathrm{Ra}=50 \mu \mathrm{m}$ for water (1cSt) and oil (48cSt). In Figures 1(b) and 1(c), $B$ is the width of volute, $y$ the distance between the impeller 


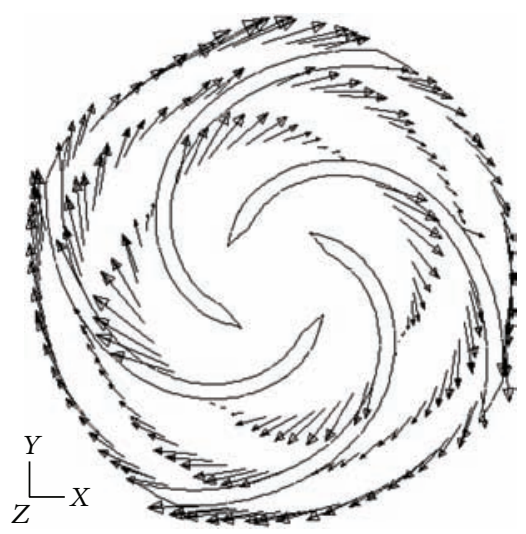

(a)

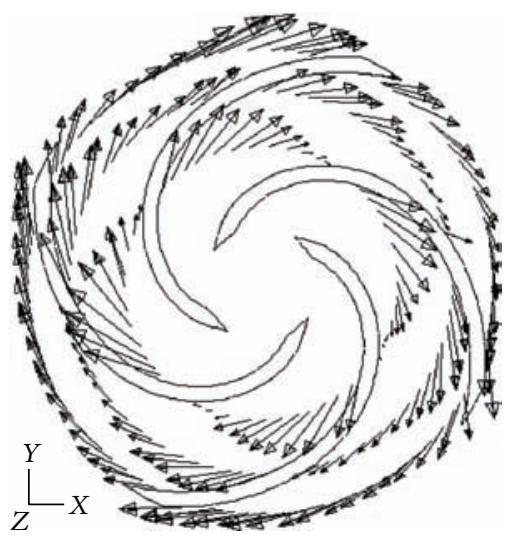

(c)

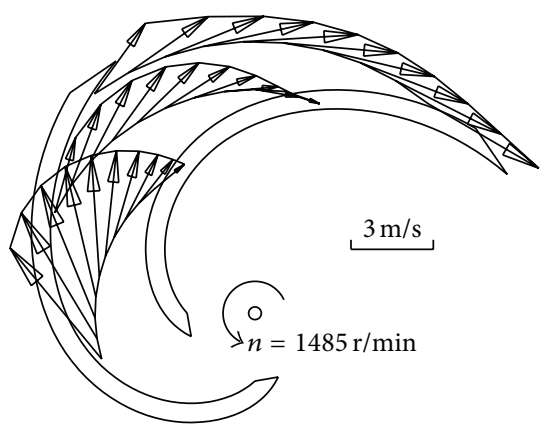

(b)

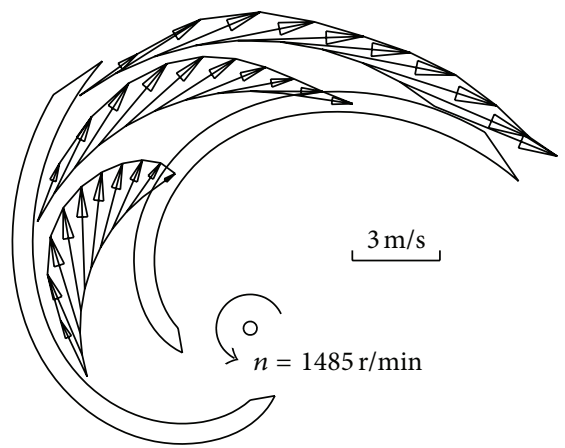

(d)

FIGURE 4: Relative velocity vectors in the impeller passages at BEP and Ra $=50 \mu \mathrm{m}$ for water (1cSt) and oil (48cSt), (a) CFD, water, (b) LDV, water, (c) CFD, oil, and (d) LDV, oil.

outlet and the observation point, $z$ the distance from the one side wall of volute to the observation point, and $V_{u}$ the circumferential component of fluid velocity in the volute throat. Compared with the velocity profiles measured, the computed velocity distributions show considerable change along the spanwise direction $(z)$ of volute near the impeller outlet and fall off substantially in the radial $(y)$ direction. The velocity on the line of $y=2 \mathrm{~mm}$ agrees well with the LDV observation. Note that the predicted velocity profile of viscous oil slightly differs from that of water once again.

Because the flows in the side chambers between the impeller outside surface and the volute casing are omitted in CFD computations, the effect of impeller outside surfaces driving fluid particles to rotate in the chambers is excluded. As a result, the computational velocity shows a quick decline in the radial direction and along the volute span.

3.2. Slip Factor. The slip factors extracted by using the foregoing methods are shown as a function of flow rate in Figure 6 at four viscosities and the surface roughness of $\mathrm{Ra}$ $=50 \mu \mathrm{m}$. The slip factor $\sigma_{\Delta}$ and $\sigma_{H}$ largely depend on flow rate rather than viscosity. $\sigma_{\Delta}$ and $\sigma_{H}$ show very different relationships with flow rate. The slip factors $\sigma_{\Delta}$ is reduced with increasing flow rate. This characteristic is the same as those revealed in the experiments conducted in [2,3]. The slip factor $\sigma_{\Delta}$ approaches asymptotically the Wiesner slip factor when flow rate is more than $6.0 \mathrm{~L} / \mathrm{s}$.

The slip factor $\sigma_{H}$ estimated by using the impeller theoretical head of $3 \mathrm{D}$ viscous flow is close to the Stodola slip factor at BEP. Moreover, the slip factor $\sigma_{H}$ exhibits a large value at high and low flow rates.

The slip factors $\sigma_{\Delta}$ and $\sigma_{H}$ are plotted against the Reynolds number $\operatorname{Re}\left(=u_{2} D_{2} / 2 v, v\right.$ is the kinematic viscosity of liquid) in Figure 7 to show their dependence on liquid viscosity. The dependence of $\sigma_{H}$ on viscosity is more evident than $\sigma_{\Delta}$. Even though $\sigma_{\Delta}$ is less viscosity dependent, it still declines with increasing viscosity (reducing Re).

In Figure 7, the Stodola, Wiesner, Pfleiderer, and Ohta slip factors have been presented as well. The Pfleiderer slip factor is not a slip factor but a head correction, which is related to the slip factor defined in (1) by the following expression:

$$
\begin{gathered}
\sigma=\left(\frac{P}{1+P}\right)\left(1-\frac{v_{r 2}}{u_{2} \tan \beta_{2 b}}\right), \\
P=2\left(\frac{\varphi}{Z}\right)\left[\frac{1}{1-\left(R_{1} / R_{2}\right)^{2}}\right], \\
\varphi=(0.55 \sim 0.68)+0.6 \sin \beta_{2 b},
\end{gathered}
$$




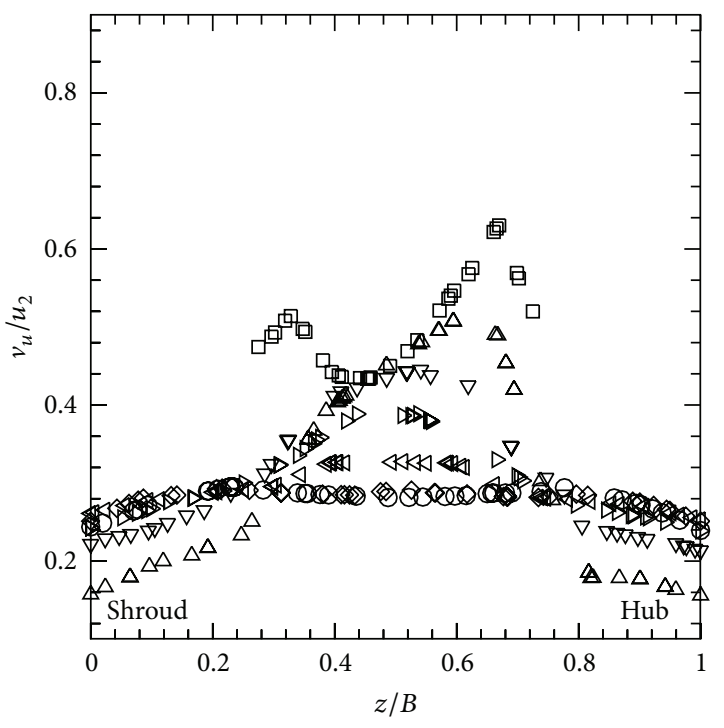

(a) CFD, VIII

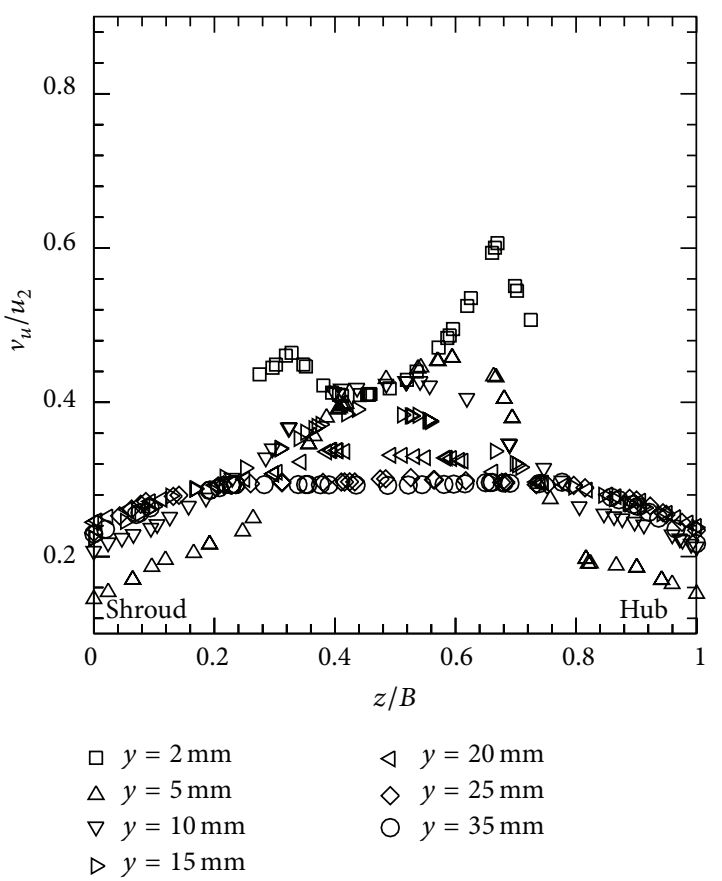

(c) CFD, VIII

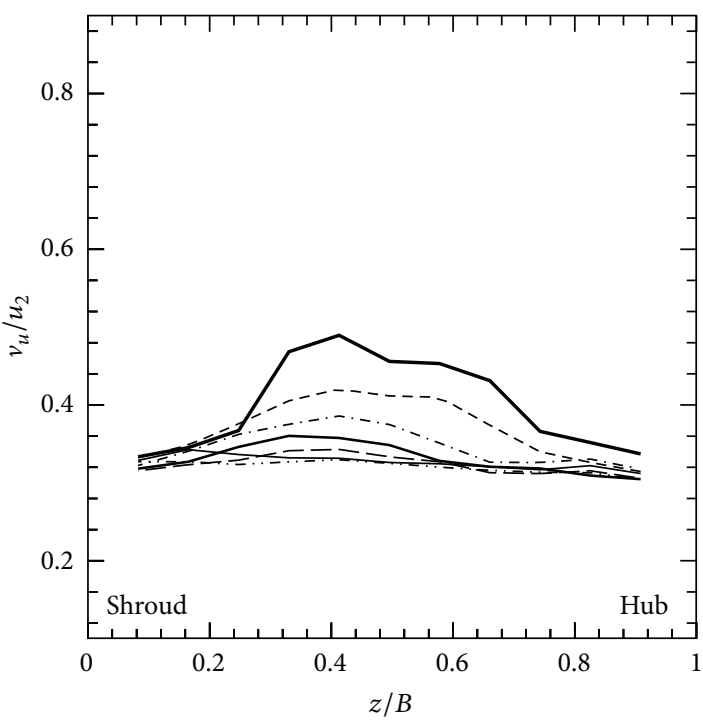

(b) LDV, VIII

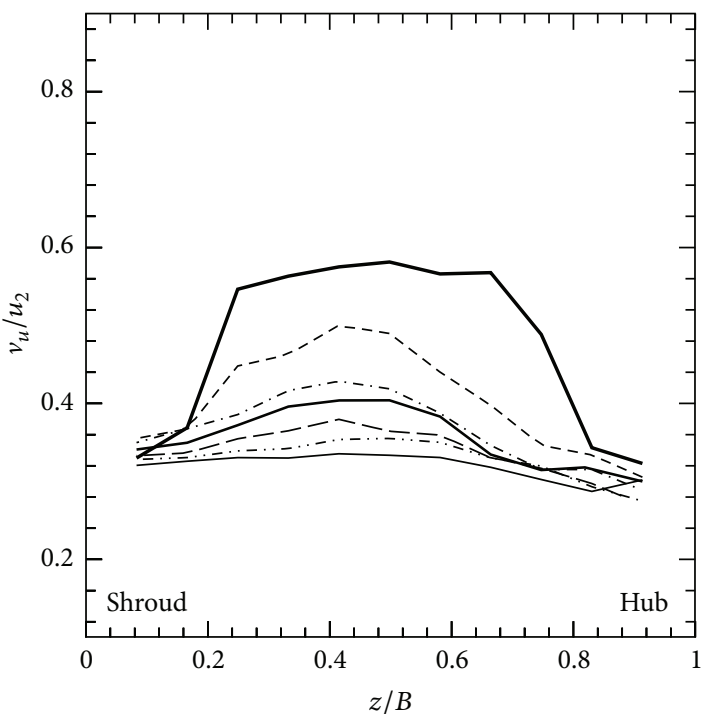

$$
\begin{aligned}
& \text { — } y=2 \mathrm{~mm} \quad-\quad y=20 \mathrm{~mm} \\
& \text { - - } y=5 \mathrm{~mm} \\
& \text {.... } y=25 \mathrm{~mm} \\
& \text {-.. } y=10 \mathrm{~mm} \\
& \text { — } y=15 \mathrm{~mm}
\end{aligned}
$$

(d) LDV, VIII

FIGURE 5: Measured and predicted circumferential velocity of fluid in volute throat at BEP and $\mathrm{Ra}=50 \mu \mathrm{m}$ for water $(1 \mathrm{cSt})$ and oil $(48 \mathrm{cSt})$, (a) CFD, water, (b) LDV, water, (c) CFD, oil, and (d) LDV, oil.

where $P$ and $\varphi$ expressions are taken from [29], and the first coefficient in $\varphi$ is chosen to be $0.6 . R_{1}$ is the radius of blade leading edge at the mid-span, and $R_{2}$ is the radius of blade trailing edge at the mid-span too, $R_{2}=D_{2} / 2$.

The Ohta slip factor is totally empirical based on the flow fields behind 20 semiopen impellers measured by means of three-hole probe when the pump handling water and viscous oils and is given by the following expressions [17]:

$$
\begin{gathered}
\sigma=a e^{b \mathrm{Z}}, \\
a=0.501 \beta_{2 b}+0.308 \log _{10} \operatorname{Re}-1.12,
\end{gathered}
$$

$$
\begin{aligned}
b= & \left(0.0289 \beta_{2 b}+0.00295\right) \log _{10} \operatorname{Re} \\
& -\left(0.147 \beta_{2 b}+0.209\right) .
\end{aligned}
$$

In Figure 7, the Stodola slip factor is nearly the same as the Pfleiderer factor but is slightly larger than the Wiesner factor. The Ohta slip factor is valid just as $\operatorname{Re} \in\left(1.78 \times 10^{4}, 1.07 \times 10^{5}\right)$ [17]. When Re is higher than $1.07 \times 10^{5}$, the Ohta slip factor seems too large compared with the rest slip factors; further it depends largely on Reynolds number. 


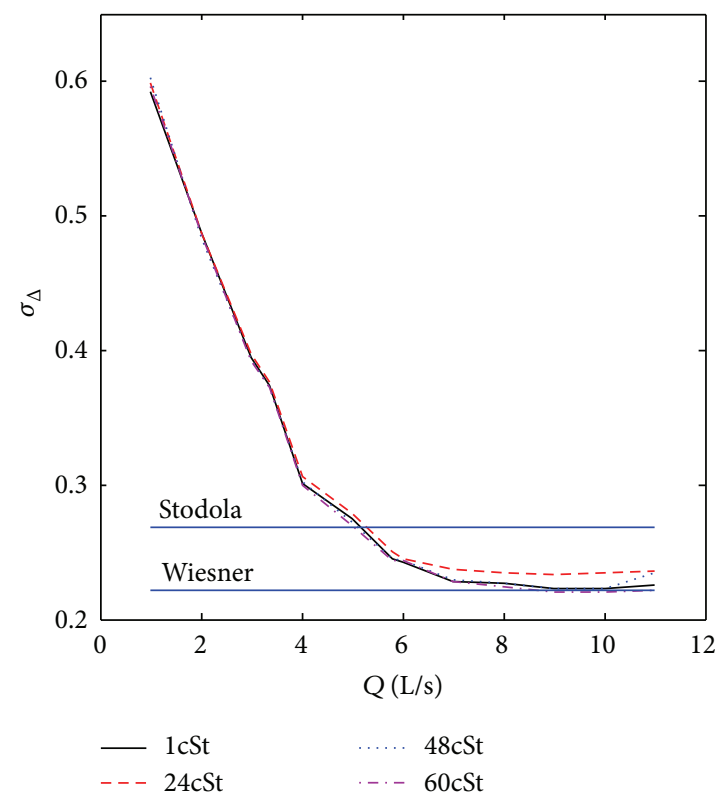

(a)

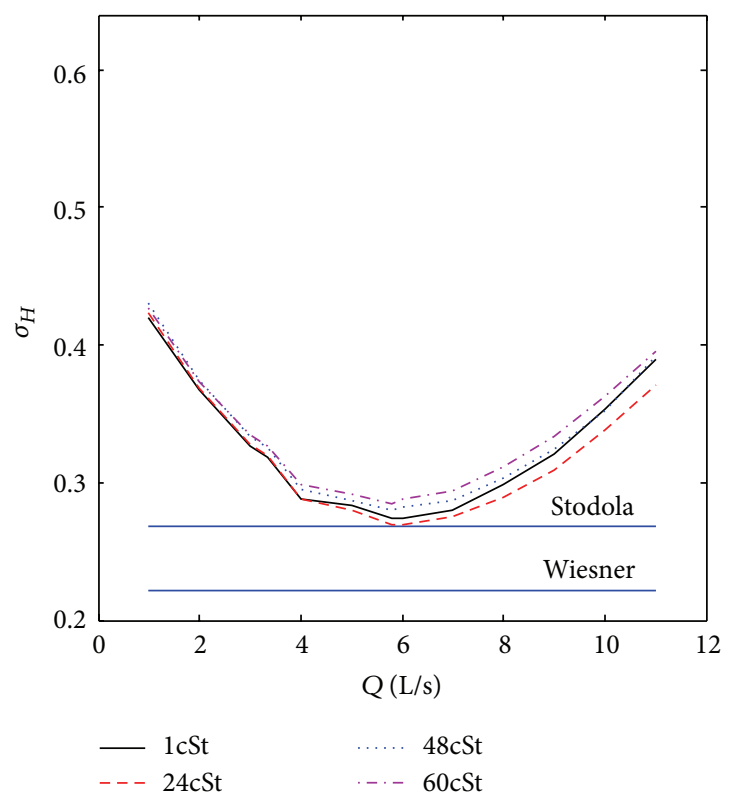

(b)

FIGURE 6: Slip factors against flow rate at four viscosities and $\mathrm{Ra}=50 \mu \mathrm{m}$ roughness, (a) based on velocity triangle at impeller outlet, (b) from impeller theoretical head of 3D viscous flow.

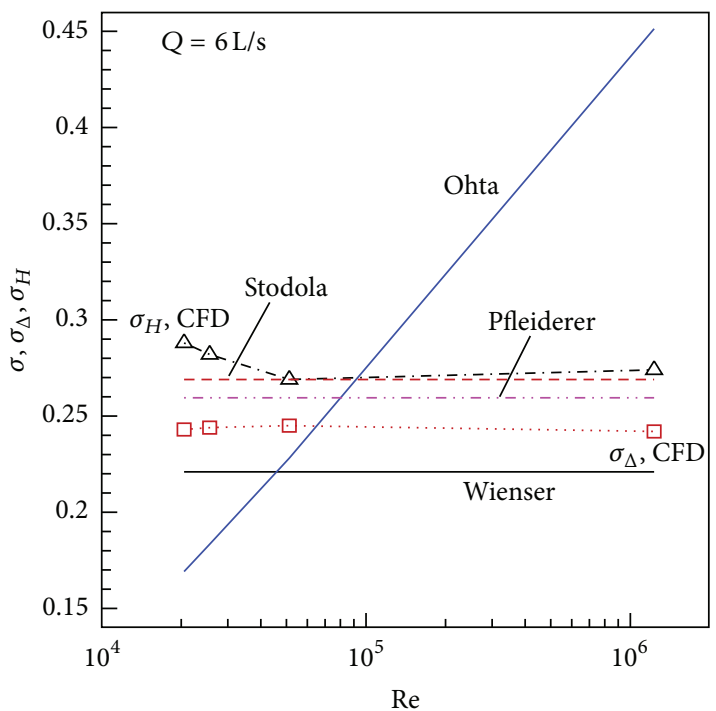

Figure 7: Various slip factors in terms of Reynolds number at BEP.

3.3. Impeller Theoretical Head and Hydraulic Efficiency Curves. The impeller theoretical head $H_{i}$ hydraulic efficiency $\eta_{h i}$ are demonstrated in Figure 8 in terms of flow rate at the kinematical viscosities of $1 \mathrm{cSt}, 24 \mathrm{cSt}, 48 \mathrm{ct}$, and $60 \mathrm{cSt}$ and with the wetted surface roughness of $\mathrm{Ra}=50 \mu \mathrm{m}$. For comparison, the theoretical head of one-dimensional inviscid fluid flow derived from the Euler's equation for turbomachinery and the Wiesner and Stodola slip factors are presented too.

The impeller theoretical head of 3D viscous flow significantly differs from $1 \mathrm{D}$ inviscid flow. The impeller theoretical head of viscous flow no longer increases linearly with decreasing flow rate; as a result of this, a maximum head occurs at the flow rate of $4.0 \mathrm{~L} / \mathrm{s}$ (around $57 \%$ the flow rate at BEP) instead, causing a stall operational condition emerges there. Such a theoretical head variation characteristic agrees well with that in the experiments carried out by Acosta and Hollander [30] and Peck [31].

The impeller theoretical head of $1 \mathrm{D}$ inviscid flow based on the Stodola slip factor is in good agreement with those of $3 \mathrm{D}$ viscous flow given by CFD, especially nearly at $Q$ $=6.0 \mathrm{~L} / \mathrm{s}$. Note that the head based on the Wiesner factor is overpredicted substantially, suggesting the Stodola's slip factor is more suitable for the impellers with less number of blades and small exit blade angle.

The impeller theoretical head is viscosity dependent. Except at a viscosity of $v=24 \mathrm{cSt}$, the theoretical head of $3 \mathrm{D}$ viscous flow is degraded with increasing viscosity. At $v=$ $24 \mathrm{cSt}$, however, the situation is quite different. In that case, the theoretical head is higher than water $(\nu=1 \mathrm{cSt})$, causing the sudden-rising head effect, as flow rate is higher than $4.0 \mathrm{~L} / \mathrm{s}$.

The impeller hydraulic efficiency $\eta_{h i}$ achieves maximum values ranged in $0.75-0.9$ at $Q=6.0-7.0 \mathrm{~L} / \mathrm{s}$. Further the impeller hydraulic efficiency is better at $v=24 \mathrm{cSt}$ when the flow rate is more than $5.0 \mathrm{~L} / \mathrm{s}$.

\section{Discussions}

4.1. Euler Head against Total Energy Head. At the outlet of impeller, we have the following expression for fluid energy head by using the cosine rule $v_{2}^{2}=w_{2}^{2}+u_{2}^{2}-2 u_{2} w_{2} \cos \beta_{2}$ in the velocity triangle $\triangle \mathrm{ABC}$ shown in Figure 2 without considering elevation potential energy of fluid [32]

$$
\frac{p_{2}}{\rho g}+\frac{v_{2}^{2}}{2 g}=\frac{p_{2}}{\rho g}+\frac{w_{2}^{2}+u_{2}^{2}-2 u_{2} w_{2} \cos \beta_{2}}{2 g} .
$$




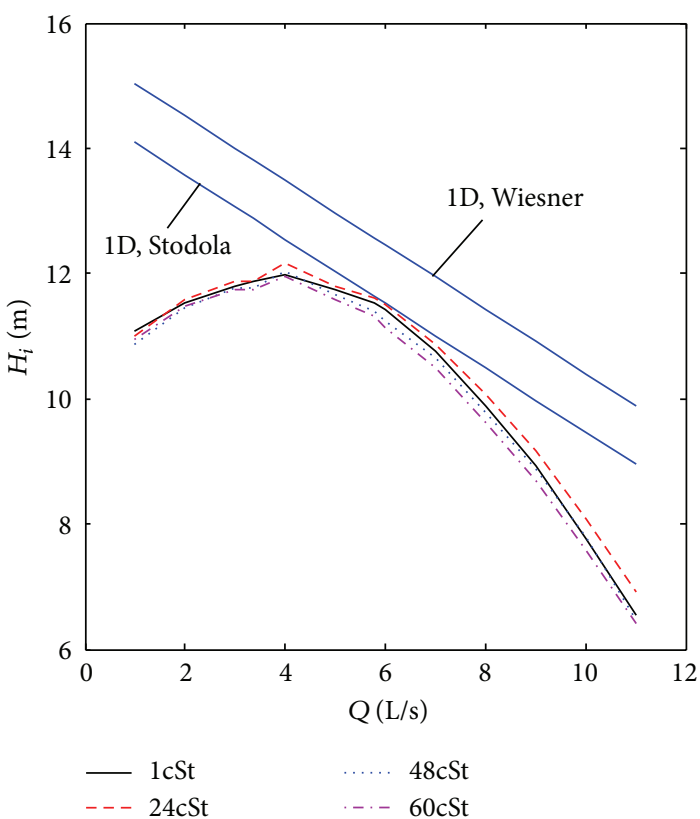

(a)

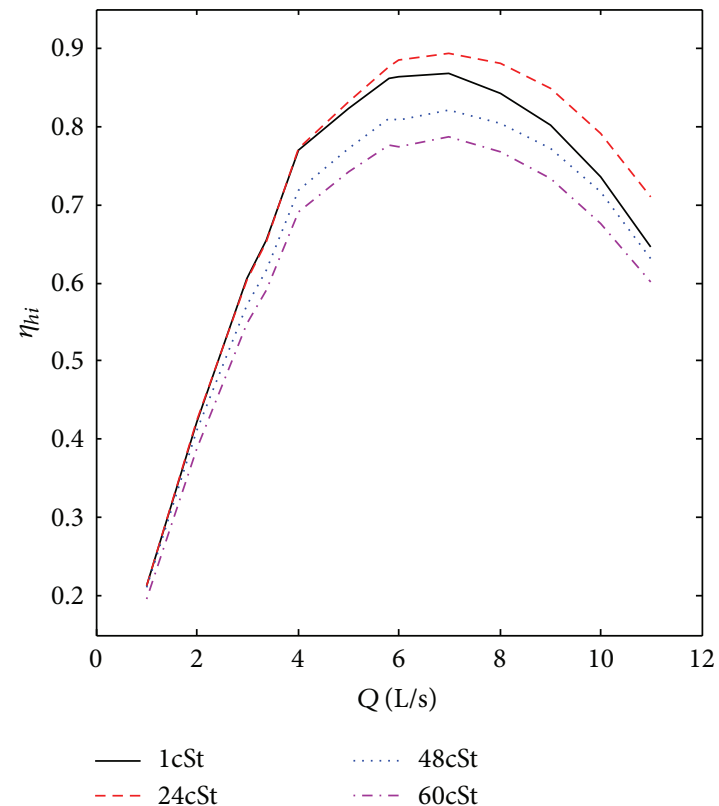

(b)

FIGURE 8: Impeller theoretical head and hydraulic efficiency in terms of flow rate at four viscosities and $\mathrm{Ra}=50 \mu \mathrm{m}$ : (a) theoretical head and (b) hydraulic efficiency.

Considering the relations $w_{u 2}=w_{2} \cos \beta_{2}$ and $w_{u 2}=u_{2}-$ $v_{u 2}$, then (11) takes the following form:

$$
\frac{p_{2}}{\rho g}+\frac{v_{2}^{2}}{2 g}=\frac{p_{2}}{\rho g}+\frac{w_{2}^{2}+u_{2}^{2}-2 u_{2}\left(u_{2}-v_{u 2}\right)}{2 g} .
$$

Rearranging the equation

$$
\frac{p_{2}}{\rho g}+\frac{v_{2}^{2}}{2 g}=\frac{p_{2}}{\rho g}+\frac{w_{2}^{2}}{2 g}-\frac{u_{2}^{2}}{2 g}+\frac{u_{2} v_{u 2}}{g} .
$$

The term $I_{2}=p_{2} / \rho g+w_{2}^{2} / 2 g-u_{2}^{2} / 2 g$ is the relative total head or rothalpy of fluid and $u_{2} v_{u 2} / g$ is the Euler head at the outlet; consequently (13) can be rewritten as

$$
\frac{p_{2}}{\rho g}+\frac{v_{2}^{2}}{2 g}=I_{2}+\frac{u_{2} v_{u 2}}{g} .
$$

Likewise, at the inlet of impeller, the fluid energy head can be expressed as the following:

$$
\frac{p_{1}}{\rho g}+\frac{v_{1}^{2}}{2 g}=I_{1}+\frac{u_{1} v_{u 1}}{g}
$$

where $I_{1}=p_{1} / \rho g+w_{1}^{2} / 2 g-u_{1}^{2} / 2 g$ is the rothalpy at the inlet of impeller. Based on (14) and (15), the relation between the Euler head rise and the total head rise can be expressed as

$$
H_{\text {Euler }}=\frac{v_{u 2} u_{2}}{g}-\frac{v_{u 1} u_{1}}{g}=H_{i}+I_{1}-I_{2}
$$

where the fluid energy head rise, that is, impeller theoretical head $H_{i}=\left(p_{2} / \rho g+v_{2}^{2} / 2 g\right)-\left(p_{1} / \rho g+v_{1}^{2} / 2 g\right)$. For an ideal (inviscid and incompressible) fluid flow, there are no

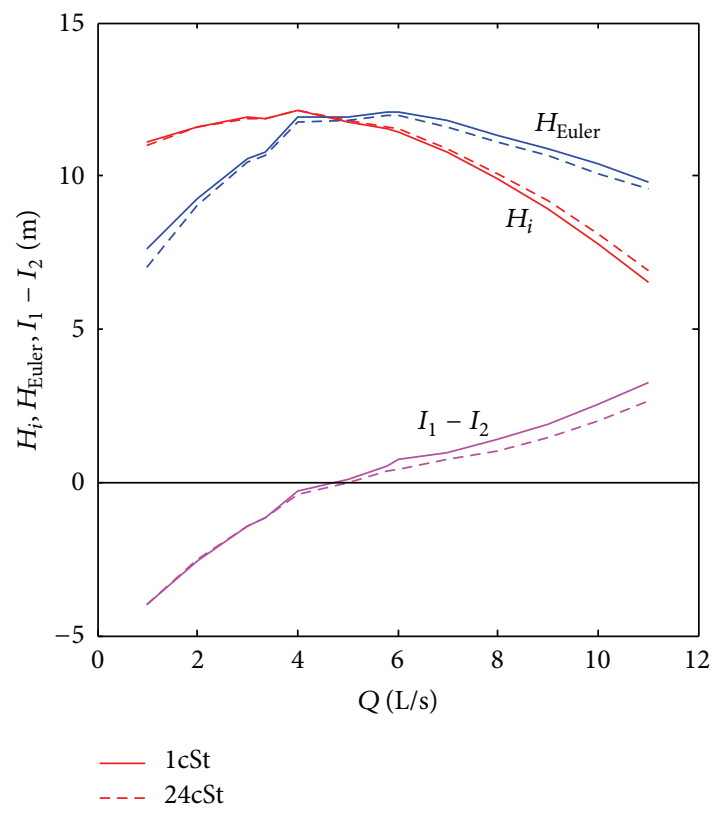

FIGURE 9: Euler head and total energy head developed in the impeller and rothalpy plotted as a function of flow rate at two viscosities of $1 \mathrm{cSt}$ and $24 \mathrm{cSt}$ as well as $\mathrm{Ra}=50 \mu \mathrm{m}$.

hydraulic losses in the impeller at all, suggesting $I_{1}=I_{2}$ and $H_{\text {Euler }}=H_{i}$; for a viscous fluid flow, however, $I_{1}>I_{2}$ and $H_{\text {Euler }}>H_{i}$.

$H_{i}, H_{\text {Euler }}$, and $I_{1}-I_{2}$ are shown in Figure 9 in terms of flow rate at the viscosities of 1cSt and 24cSt. Clearly, $H_{i}$ differs from $H_{\text {Euler }}$ in the figure. Moreover $I_{1}-I_{2}$ is somehow 


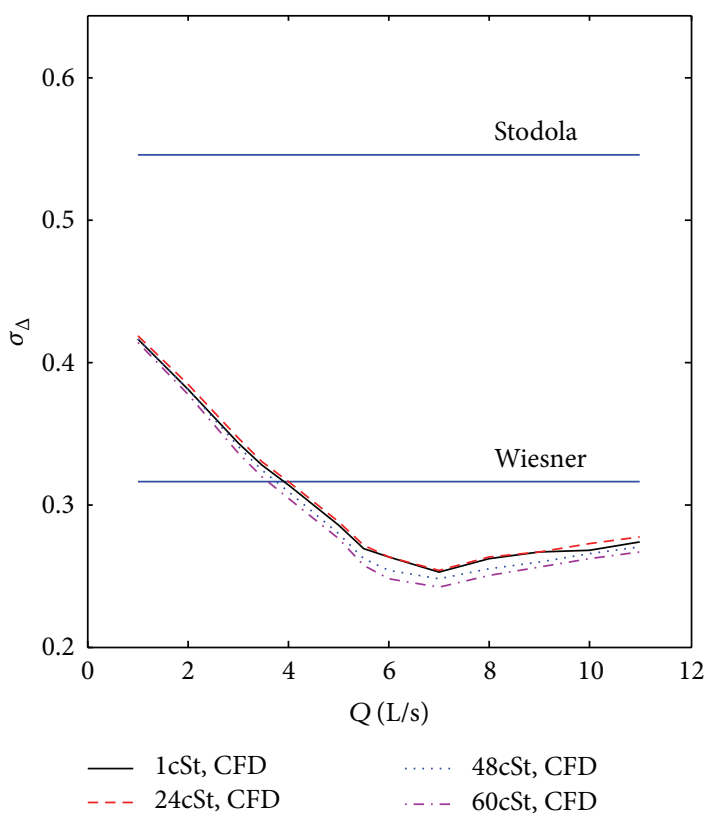

(a)

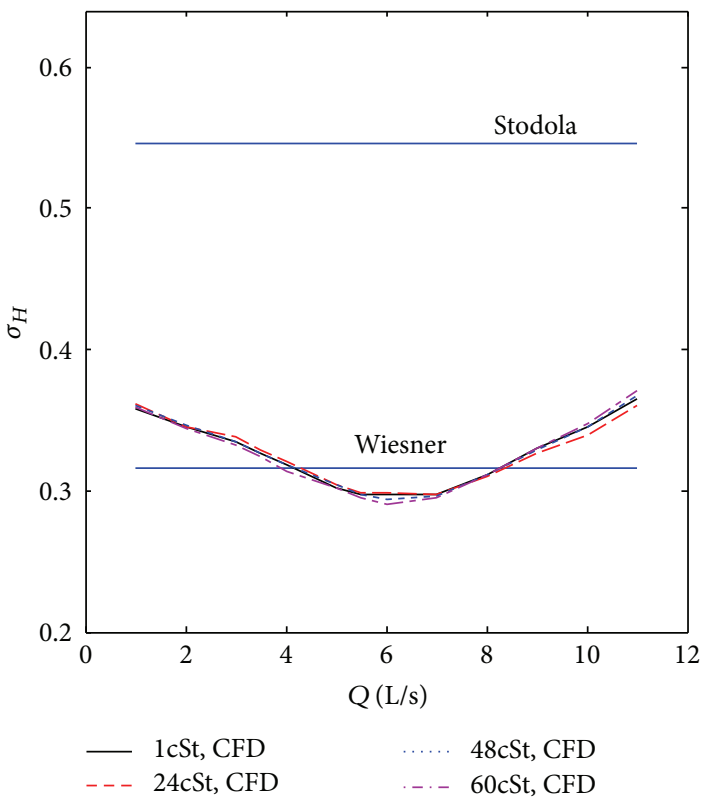

(b)

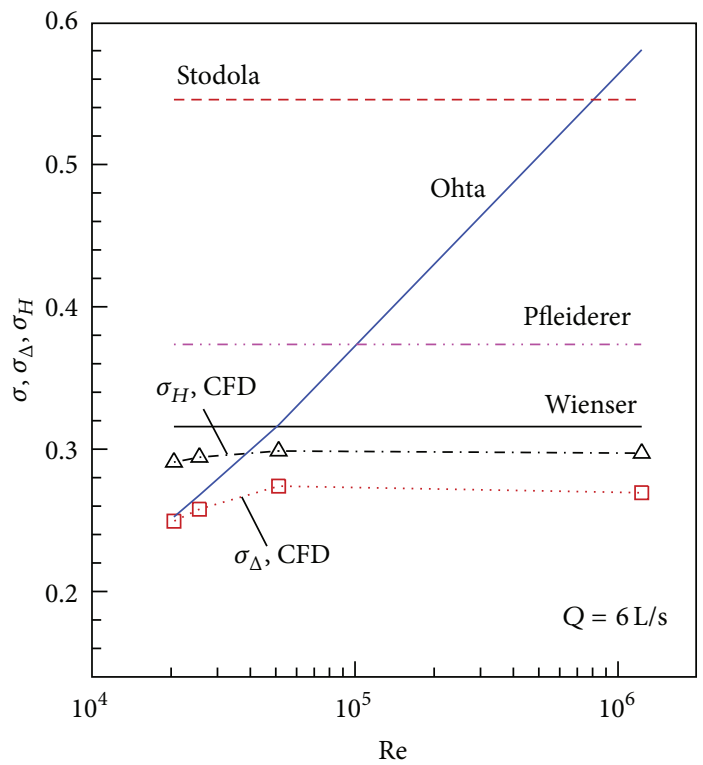

(c)

FIGURE 10: Various slip factors in terms of flow rate and Reynolds number at BEP for impeller with $\beta_{2 b}=44^{\circ}$, (a) based on velocity triangle at impeller outlet, (b) from impeller theoretical head of 3D viscous flow, (c) at BEP.

less than zero as the flow rate is lower than $5.0 \mathrm{~L} / \mathrm{s}$. Just beyond that flow rate $I_{1}-I_{2}$ becomes positive. In fact, $I_{1}-I_{2}$ represents the hydraulic losses in the impeller and should be positive at all the flow rates. Unfortunately, it is really hard to understand that FLUENT somehow gives a negative $I_{1}-I_{2}$, which was observed in [20] as well. At the rest viscosity, the same situation remains.

Since the Euler head is different from the energy head for a viscous fluid, a slip factor from velocity triangle must be different from that based on the theoretical head of impeller even at design or BEP condition. The experimental data in [4, 17] confirmed that there is a difference in the two slip factors.
4.2. Effect of Exit Blade Angle on Slip Factor. The flow field of water and viscous oils in the pump with $44^{\circ}$ exit blade angle was computed to identify the effect of the blade angle on slip factor. Except the exit blade angle and wrap angle, the rest of geometrical parameters of the impeller and volute were kept the same as the pump with $20^{\circ}$ exit blade angle. Two slip factors extracted from the CFD results are illustrated in Figure 10 as a function of flow rate and in terms of Reynolds number at $Q=6.0 \mathrm{~L} / \mathrm{s}(\mathrm{BEP})$, respectively.

Compared with the slip factors shown in Figure 6, the two slip factors of the impeller with larger exit blade angle are less dependent on flow rate. The Wienser rather than 


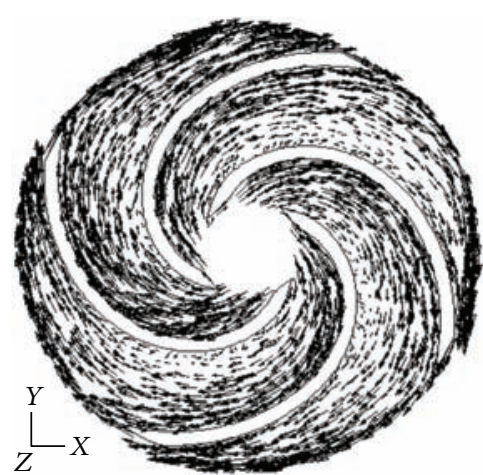

(a)

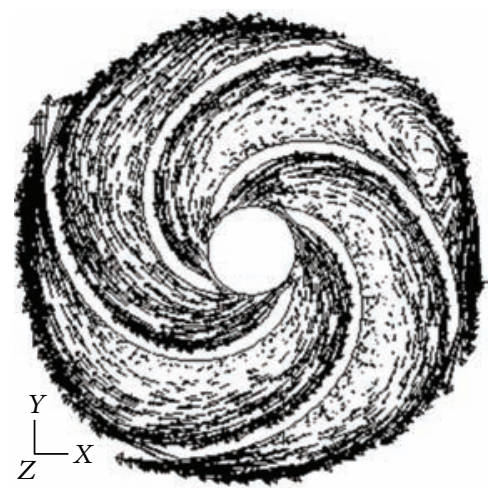

(c)

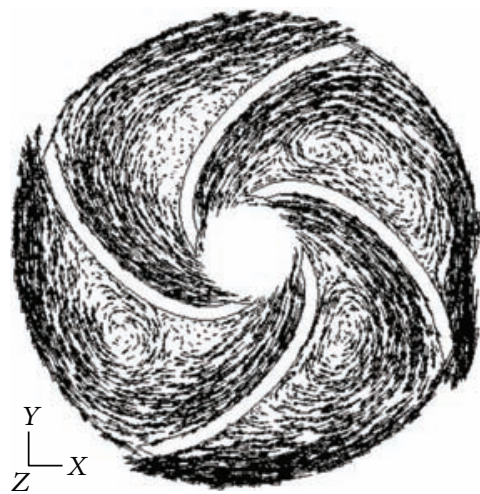

(e)

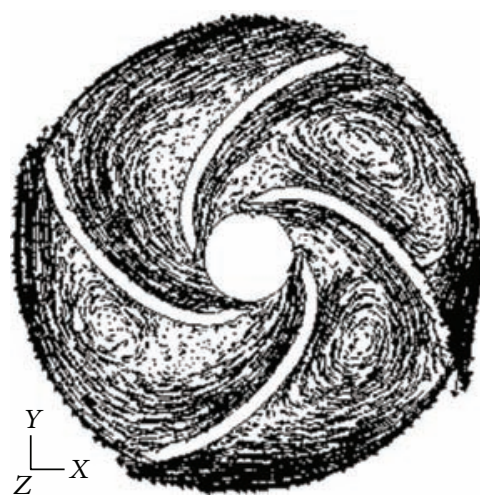

(g)

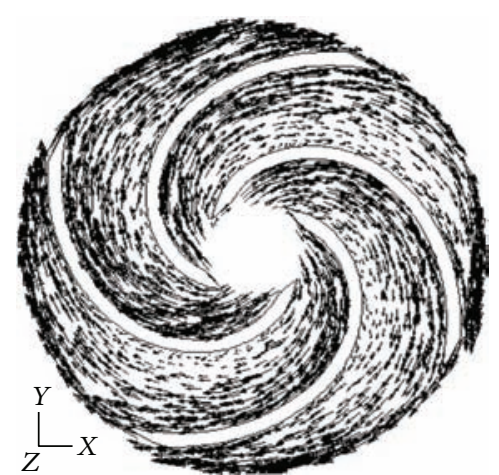

(b)

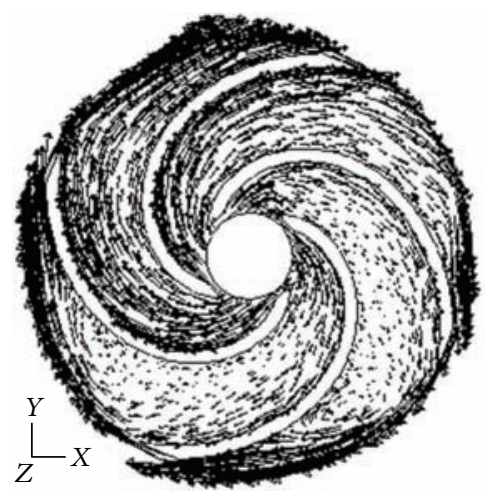

(d)

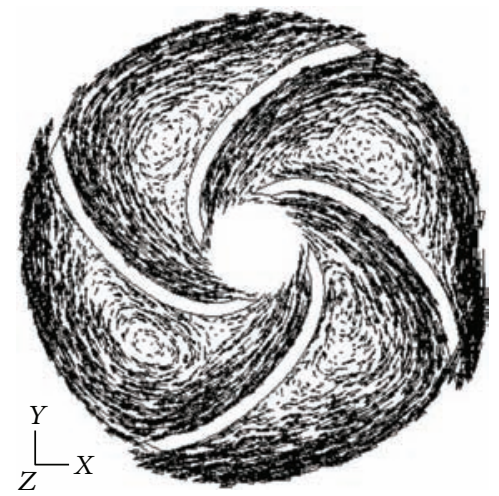

(f)

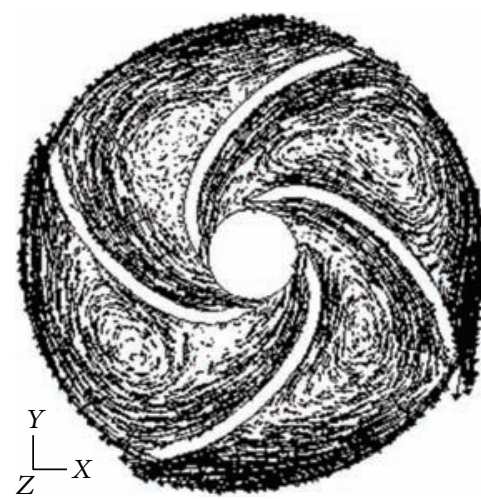

(h)

FIGURE 11: Relative velocity vectors of flow in mid-span plane of the impellers with $\beta_{2 b}=20^{\circ}, 44^{\circ}$ at $Q=3.4$, and $6.0 \mathrm{~L} / \mathrm{s}$ (BEP), (a)-(d) for $\beta_{2 b}$ $=20^{\circ}$, (e)-(h) $\beta_{2 b}=44^{\circ}$, (a), (b), (e), and (f) for BEP, and (c), (d), (g) and (h) for low flow rate $3.4 \mathrm{~L} / \mathrm{s}$, left-water (1cSt), and right-oil (48cSt). 


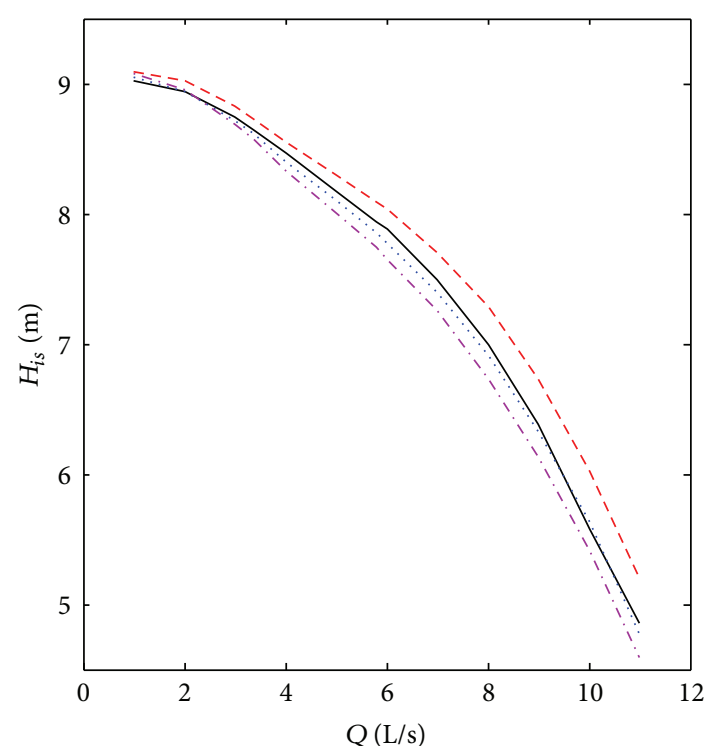

(a)

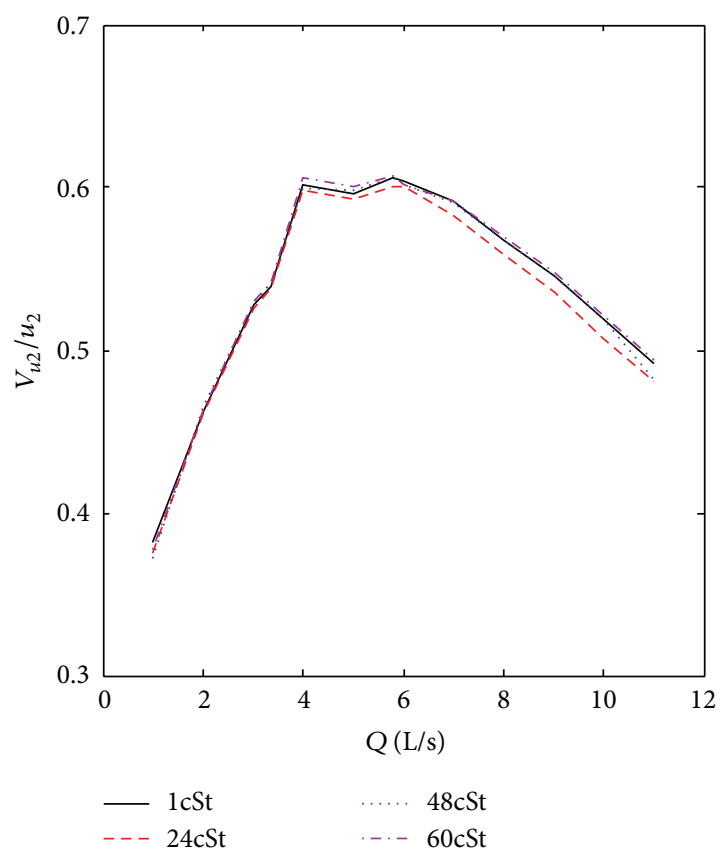

(c)

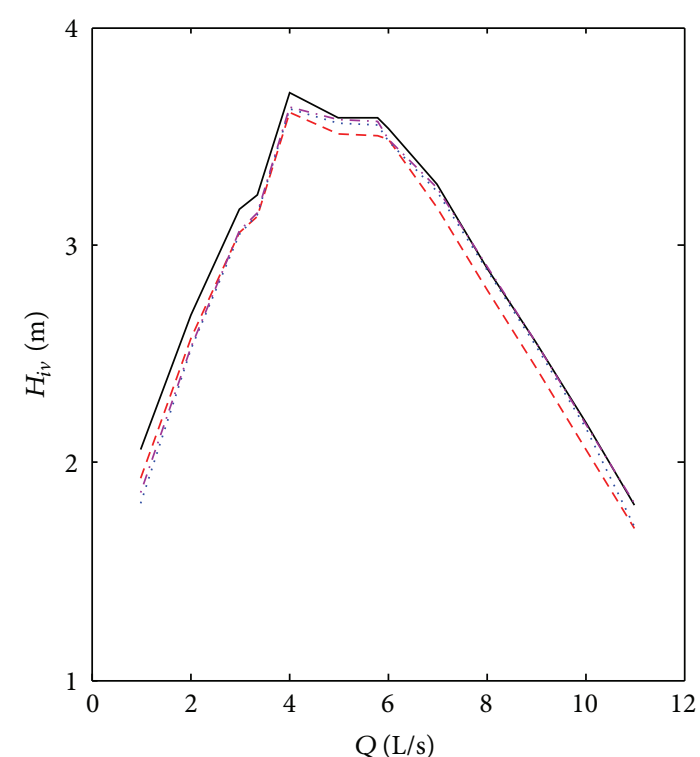

(b)

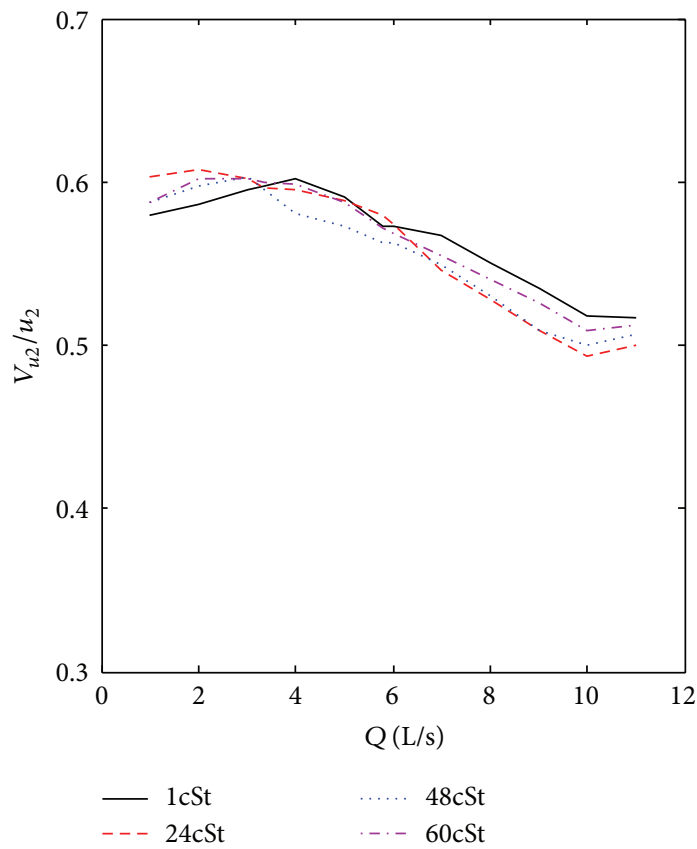

(d)

FIGURE 12: Impeller static pressure head and kinetic head rises, dimensionless tangential velocity of liquid at impeller exit at various liquid viscosities, and $\mathrm{Ra}=50 \mu \mathrm{m}$, (a) static pressure head rise, (b) kinetic head rise, (c) tangential velocity with volute, and (d) tangential velocity without volute.

Stodola slip factor seems more close to CFD prediction. In Figure 10(c), the slip factors estimated with the Stodola, Wiesner, Pfleiderer, and Ohta correlations are presented as well. The Stodola and Pfleiderer slip factors seem overpredicted.

Compared with Figure 7, a larger blade angle leads to an increased slip factor. Moreover a higher viscosity can reduce slip factor considerably for an impeller with large exit blade angle.

The relative velocity vectors in the mid-span plane of the impellers with exit blade angle $20^{\circ}$ and $44^{\circ}$ at low flow rate
$(\mathrm{Q}=3.4 \mathrm{~L} / \mathrm{s})$ and $\mathrm{BEP}$ for the viscosities of $1 \mathrm{cSt}$ and $48 \mathrm{cSt}$ are presented in Figure 11. In the impeller with large blade angle $\left(\beta_{2 b}=44^{\circ}\right)$ there are clear vortices in the flow passages even at the BEP. In the impeller with small blade angle $\left(\beta_{2 b}=20^{\circ}\right)$ the vortices emerge just at the low flow rate. A vortex increases the curvature of relative flow stream lines, causing a severe slip effect exhibits at the impeller discharge and an increased slip factor.

Since the vortices always stay in the passages of the impeller with large blade angle $\left(\beta_{2 b}=44^{\circ}\right)$, the slip factor 
is less sensitive to flow rate and it is higher than that in the impeller with small blade angle $\left(\beta_{2 b}=20^{\circ}\right)$ at BEP.

\subsection{Reason for Degraded Euler Head at Low Flow Rate. In} Figure 9, the Euler head is lower than the total energy head when $Q<5.0 \mathrm{~L} / \mathrm{s}$. To clarify the reasons behind this, the impeller static pressure head rise $H_{i s}\left(=p_{2} / \rho g-p_{1} / \rho g\right)$ and kinetic head rise $H_{i V}\left(=v_{2}^{2} / 2 g-v_{1}^{2} / 2 g\right)$ versus flow rate are illustrated in Figure 12 at various liquid viscosities and $\mathrm{Ra}=$ $50 \mu \mathrm{m}$. It can be seen that the impeller static pressure head rise increases continuously with decreasing flow rate; contrarily, the kinetic head rise achieves a maximum around $Q=$ $4.0 \mathrm{~L} / \mathrm{s}$, then exhibits a dramatic decrease. Obviously, this too low kinetic head at the low flow rate is responsible for the lower Euler head at underloading condition.

To disclose the root-cause for the small kinetic head at a low flow rate, the computed tangential velocity of liquid at the impeller outlet is illustrated in Figure 12(c) as well. The velocity component has been made dimensionless with $u_{2}$. It is clear that the tangential velocity is dramatically decreased at low flow rate. Note that the LDV measurements also revealed this effect in [28].

The reduction in tangential velocity implies that the volute has applied a strong influence on the flow around the impeller. To confirm this, the flow field of water in the impeller without a volute was computed and the tangential velocity at the impeller outlet is shown in Figure 12(d). The tangential velocity increases steadily with declining flow rate. This effect was observed in the experiment conducted by Kurokawa and Hode [33], where there was a vaneless diffuser rather than a volute behind a centrifugal impeller. Hence, it is the volute that is responsible for the reduction of tangential velocity at impeller discharge at a low flow rate.

\section{Conclusions}

Slip factor was extracted from the CFD computational outcomes by using two ways; one is from the velocity triangles at the impeller discharge and one is from the impeller theoretical head of $3 \mathrm{D}$ viscous turbulent flow. The impeller theoretical head against flow rate was compared between traditional $1 \mathrm{D}$ inviscid flow and $3 \mathrm{D}$ viscous one. The CFD computed velocity profiles are basically in agreement with LDV observations. Clearly, the slip factors given by the two methods are not consistent in numerical value. Flow rate rather than liquid viscosity show a remarked effect on the two slip factors. Volute is responsible for reduction of Euler head at low flow rates. The slip factor of impeller with large exit blade angle is less sensitive to change in flow rate because of existing vortices.

\section{References}

[1] W. G. Li, "Effect of exit blade angle, viscosity and roughness in centrifugal pumps investigated by CFD computation," TASK Quarterly, vol. 15, no. 1, pp. 21-41, 2011.

[2] T. Kasai, "On the flow conditions at the exit of centrifugal impeller," Journal of JSME, vol. 37, no. 202, pp. 60-69, 1934.
[3] T. Kasai, "On the exit velocity and slip coefficient at the outlet of centrifugal impeller with some references to the characteristics of pump," Transactions of the Japan Society of Mechanical Engineers, vol. 1, no. 3, pp. 234-246, 1935.

[4] T. Sakai and I. Watanabe, "The slip factor of centrifugal and mixed-flow compressors," Transactions of the Japan Society of Mechanical Engineers, vol. 33, no. 249, pp. 735-744, 1967.

[5] A. Noorbakhsh, "Theoretical and real slip factor in centrifugal pumps," Technical Note 93, von Karman Institute for Fluid Dynamics, 1973.

[6] A. Whitfield, "Slip factor of a centrifugal compressor and its variation with flow rate," Proceedings of the Institution of Mechanical Engineers, vol. 188, no. 32, pp. 415-421, 1974.

[7] S. Murata, T. Ogawa, and M. Gotoh, "On the flow in a centrifugal impeller: 2nd report, effects of change in impeller width," Bulletin of the JSME, vol. 21, no. 151, pp. 90-97, 1978.

[8] H. Harada and Y. Senoo, "Equations of the blade loading and the slip factor of a centrifugal impeller," Transactions of the Japan Society of Mechanical Engineers, Part B, vol. 52, no. 482, pp. 3525-3528, 1986.

[9] F. C. Visser, J. J. H. Brouwers, and R. Badie, “Theoretical analysis of inertially irrotational and solenoidal flow in two-dimensional radial-flow pump and turbine impellers with equiangular blades," Journal of Fluid Mechanics, vol. 269, pp. 107-142, 1994.

[10] T. W. von Backström, "A unified correlation for slip factor in centrifugal impellers," Journal of Turbomachinery, vol. 128, no. 1, pp. 1-10, 2006.

[11] W. C. Hassenpflug, "The incompressible two-dimensional potential flow through blades of a rotating radial impeller," Mathematical and Computer Modelling, vol. 52, no. 9-10, pp. 1299-1389, 2010.

[12] C. Ji, J. Zou, X. D. Ruan, P. Dario, and X. Fu, "A new correlation for slip factor in radial and mixed-flow impellers," Proceedings of the Institution of Mechanical Engineers, Part A, vol. 225, no. 1, pp. 114-119, 2011.

[13] X. Qiu, D. Japikse, J. Zhao, and M. R. Anderson, "Analysis and validation of a unified slip factor model for impellers at design and off-design conditions," Journal of Turbomachinery, vol. 133, no. 4, Article ID 041018, 2011.

[14] F. J. Wiesner, "A review of slip factors for centrifugal impellers," Journal of Engineering for Power, vol. 89, no. 4, pp. 558-572, 1967.

[15] Y. Sakamoto, "Slip factor dependence on flow rate in centrifugal compressors," Transactions of the Japan Society of Mechanical Engineers, Part B, vol. 49, no. 446, pp. 2242-2247, 1983.

[16] T. Toyokura, J. Kurokawa, and T. Kanemoto, "Performance improvement for centrifugal pump handling high viscosity oil," Turbomachinery, vol. 7, no. 2, pp. 72-79, 1979.

[17] H. Ohta, "Effect of reynolds number on slip factor of centrifugal pump for high-viscosity liquids," Transactions of the Japan Society of Mechanical Engineers, Part B, vol. 65, no. 639, pp. 3697-3704, 1999.

[18] E.-M. Guo and K.-Y. Kim, "Three-dimensional flow analysis and improvement of slip factor model for forward-curved blades centrifugal fan," KSME International Journal, vol. 18, no. 2, pp. 302-312, 2004.

[19] J. A. Caridad and F. Kenyery, "Slip factor for centrifugal impellers under single and two-phase flow conditions," Journal of Fluids Engineering, vol. 127, no. 2, pp. 317-321, 2005.

[20] Y. Nishi, N. Matsuo, and J. Fukutomi, "Loss analysis of a new type of sewage pump," Journal of Environment and Engineering, vol. 4, no. 2, pp. 362-374, 2009. 
[21] H. A. Elsheshtawy, "Numerical study of slip factor in centrifugal pumps ad study factors affecting its performance," in Proceedings of the 1st International Conference on Mechanical Engineering and Material Science, pp. 103-106, 2012.

[22] J. M. Huang, K. W. Luo, C. F. Chen et al., "Numerical investigations of slip phenomena in centrifugal impellers," International Journal of Turbo \& Jet-Engines, vol. 30, no. 1, pp. 123-132, 2013.

[23] J. P. Veres, "Centrifugal and axial pump design and off-design performance prediction," NASA Technical Memorandum 106745, 1994.

[24] Y.-D. Choi, J. Kurokawa, and J. Malsui, "Performance and internal flow characteristics of a very low specific speed centrifugal pump," Journal of Fluids Engineering, vol. 128, no. 2, pp. 341-349, 2006.

[25] C. E. Brennen, Hydrodynamics of Pumps, Oxford University Press, Oxford, UK, 1994.

[26] W. G. Li and Z. M. Hu, "Experiments on the performance of centrifugal oil pump," Chinese Fluid Machinery, vol. 25, no. 2, pp. 3-8, 1996.

[27] W.-G. Li, "Effects of viscosity of fluids on centrifugal pump performance and flow pattern in the impeller," International Journal of Heat and Fluid Flow, vol. 21, no. 2, pp. 207-212, 2000.

[28] W.-G. Li, "Flow of viscous oil in the volute of a centrifugal pump," Journal of Thermal Science, vol. 11, no. 1, pp. 10-15, 2002.

[29] S. Lazarkiewicz and A. T. Troskolanski, Impeller Pumps, Pergamon Press, Oxford, UK, 1965.

[30] A. J. Acosta and A. Hollander, "Observations on the performance of centrifugal pumps at low Reynolds numbers," in Proceedings of the Symposium on Pump Design, Testing and Operation, Glasgow, UK, 1965.

[31] J. F. Peck, "Investigation concerning flow conditions in a centrifugal pump and effect of blade loading on head slip," Proceedings of Institution of Mechanical Engineers, vol. 164, no. 1, pp. 1-30, 1951.

[32] J. F. Gulich, Centrifugal Pumps, Springer, Heidelberg, Germany, 2010.

[33] J. Kurokawa and S. Hode, "Prediction of outlet flow characteristics of centrifugal impellers," Bulletin of the JSME, vol. 28, no. 241, pp. 1423-1429, 1985. 

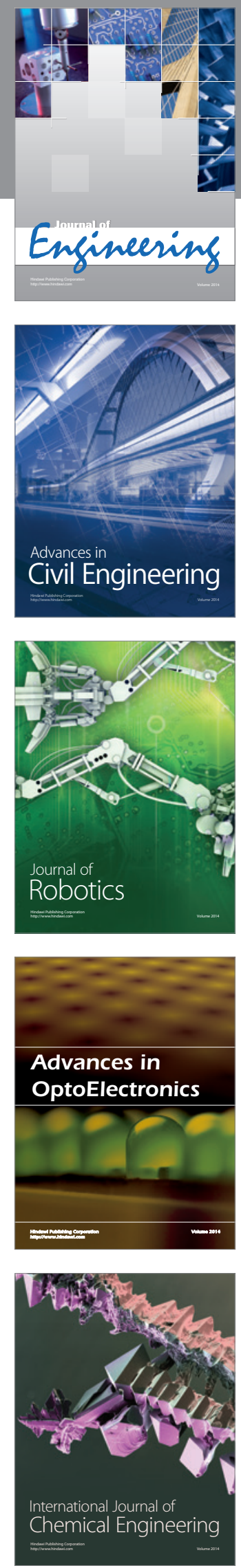

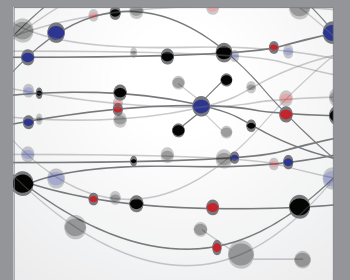

The Scientific World Journal
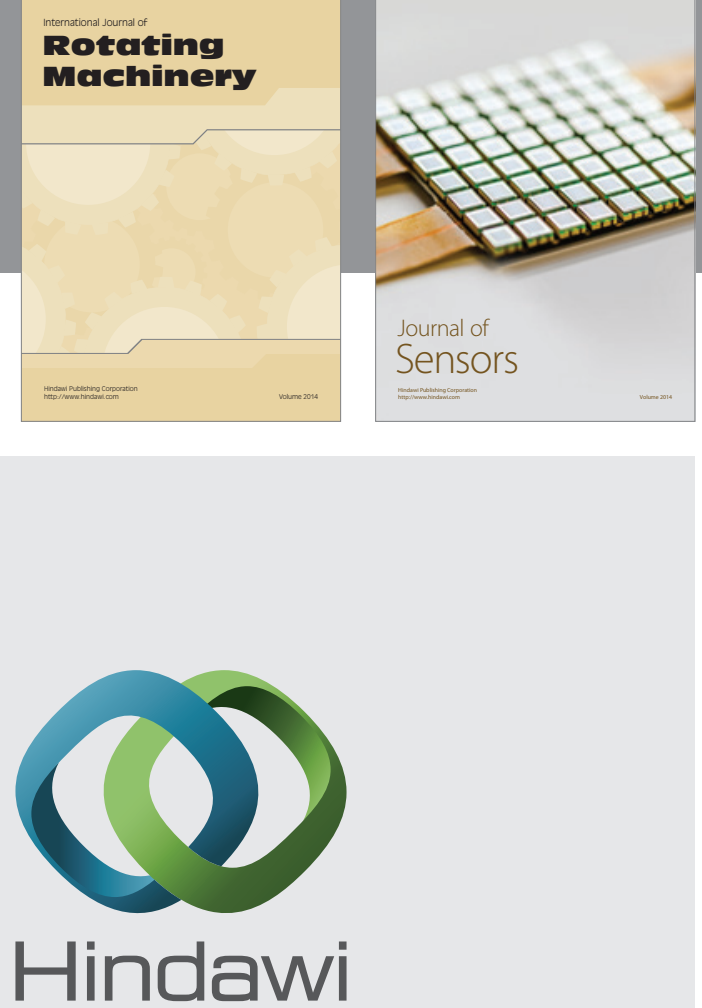

Submit your manuscripts at http://www.hindawi.com
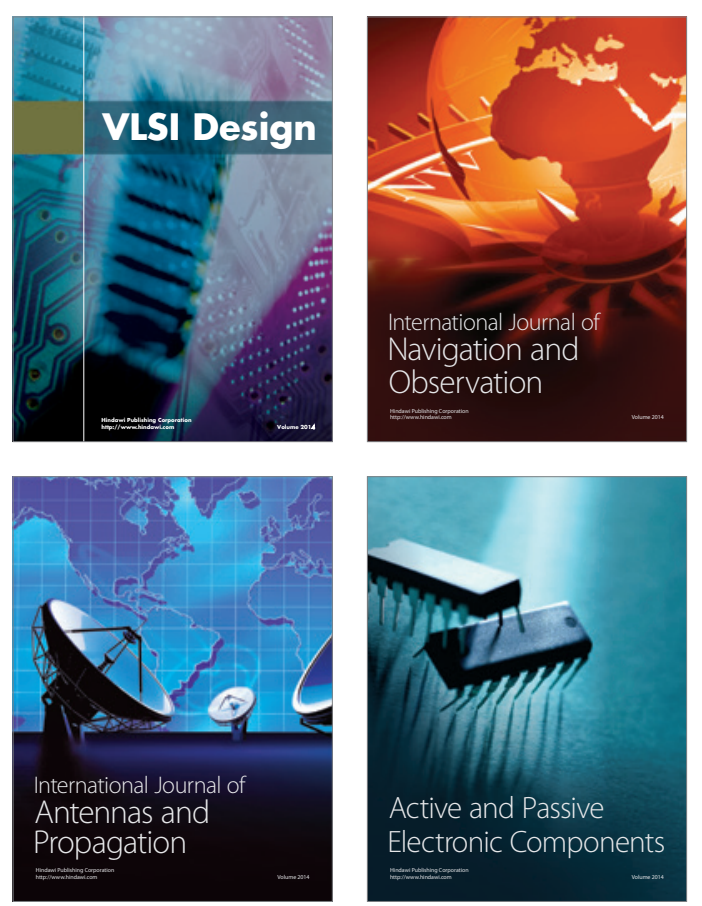
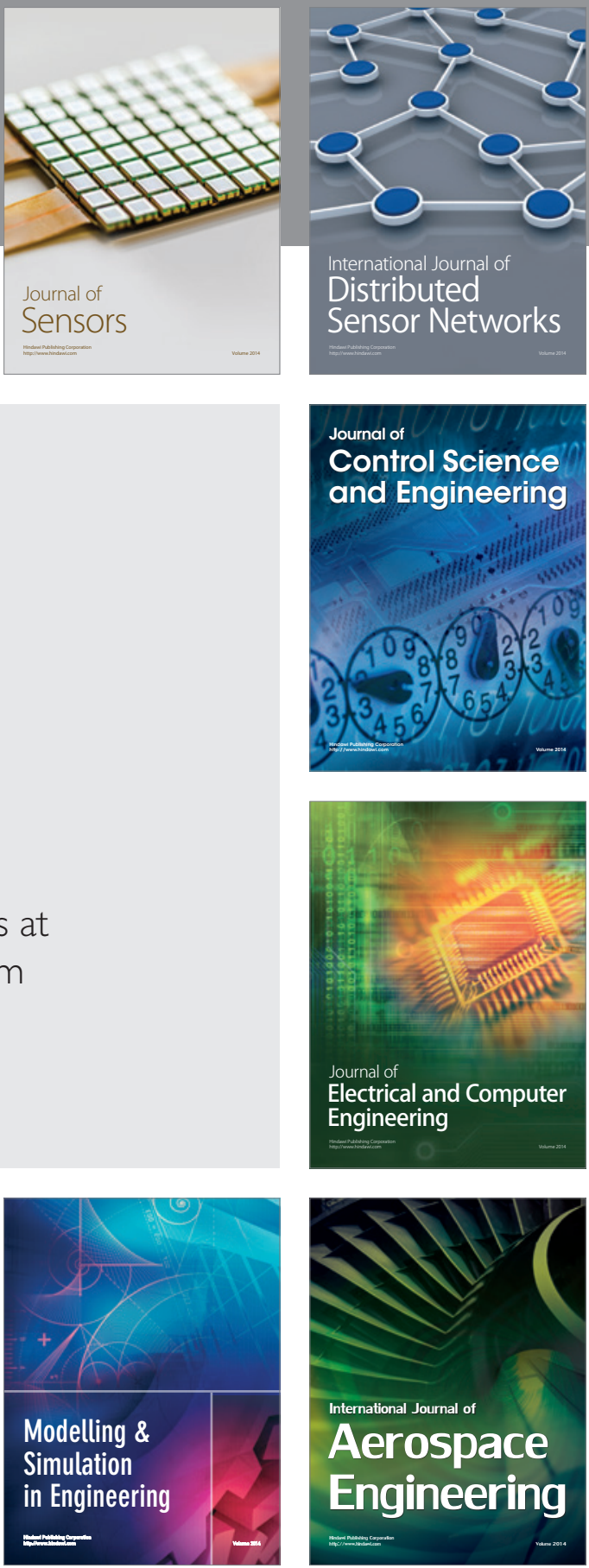

Journal of

Control Science

and Engineering
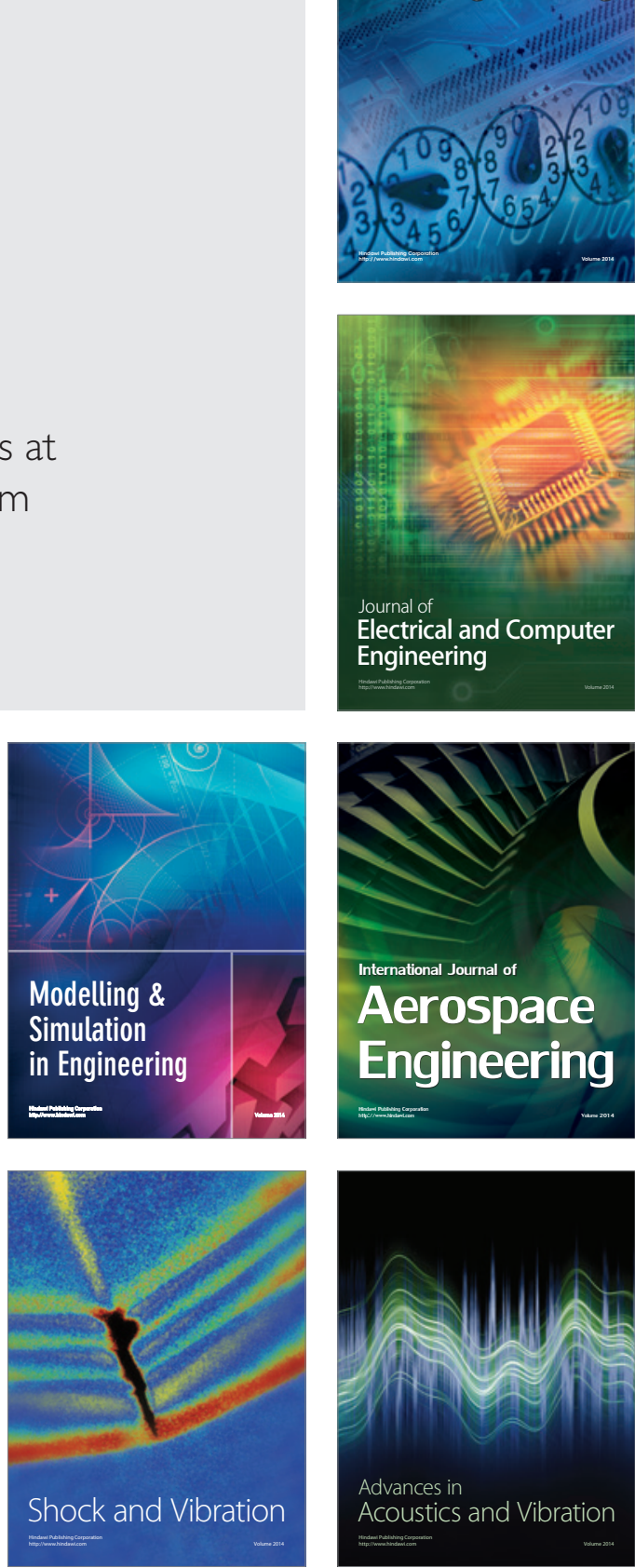